\title{
RE-DESAIN AREA SENI PERTUNJUKAN GELANGGANG REMAJA BULUNGAN
}

\author{
Joerynda Putri Wijayakusuma ${ }^{1)}$, Stephanus Huwae ${ }^{2)}$ \\ 1) Program Studi S1 Arsitektur, Fakultas Teknik, Universitas Tarumanagara, joerynda20@gmail.com \\ 2) Program Studi S1 Arsitektur, Fakultas Teknik, Universitas Tarumanagara, ituthuwae@gmail.com
}

\begin{abstract}
Abstrak
Gelanggang Remaja Jakarta Selatan (GRJS) merupakan wadah eksplorasi dan aktivitas bagi para remaja di bidang seni, budaya dan olahraga yang memiliki potensi untuk dijadikan tempat wisata sebagai bentuk dukungan untuk memperkenalkan warisan budaya yang kaya serta mencerminkan sejarah dan keberagaman etnis indonesia. Namun, dikarenakan fasilitas yang sudah tidak lagi mampu mewadahi minat dan bakat serta tidak memenuhi standard menjadikan GRJS tidak dapat berkembang menjadi destinasi wisata yang berfokus pada seni pertunjukan yang telah dilupakan dari tahun ke tahun. Maka itu dengan dilakukannya redesain diharapkan dapat mengembalikan kehadiran seni serta mengembangkan kawasan Bulungan.
\end{abstract}

Kata kunci: re-desain, seni pertunjukan, wisata

\begin{abstract}
Gelanggang Remaja Jakarta Selatan (GRJS) is a place of exploration and activity for youth in the arts, cultures and sports that have the potential to be a tourist attraction as a form of support to introduce rich cultural heritage and reflect the Indonesian history and diversity. However, due to a facility that no longer has been able to do the interests and talents and does not fulfill the standard makes the GRJS unable to progress to a tourist destination that focuses on the art of performance that has been forgotten over the years. The re-design is expected to restore the presence of the arts and expand the Bulungan district.
\end{abstract}

Keywords: performing arts, re-design, tourism

\section{PENDAHULUAN}

\section{Latar Belakang}

Pariwisata merupakan salah satu sektor ekonomi yang penting di berbagai negara terutama di Indonesia. Pariwisata menempati urutan ketiga dalam hal penerimaan devisa setelah komoditi minyak dan gas bumi1. Kekayaan alam dan budaya merupakan komponen penting dalam pariwisata di Indonesia. Beberapa tempat wisata di Jakarta didukung dengan warisan budaya yang kaya serta mencerminkan sejarah dan keberagaman etnis Indonesia.

Menurut data dari data.jakarta sejak 2010 hingga 2016 setiap tahunnya jumlah wisatawan yang datang ke DKI Jakarta terus meningkat. Gelanggang Remaja Jakarta Selatan (GRJS) merupakan wadah eksplorasi dan aktivitas bagi para remaja di bidang seni, budaya dan olahraga. Terletak di belakang jalan arteri sekunder kota Jakarta, kelurahan Kramat Pela, Kecamatan Kebayoran Baru menjadikan GRJS tempat yang strategis untuk dikunjungi. Selain itu, Gelanggang Remaja Jakarta Selatan Bulungan memiliki potensi yang sangat besar untuk dijadikan tempat wisata dengan atraksi yang sudah terjadi di dalamnya. Namun, dikarenakan fasilitas yang sudah tidak lagi mampu mewadahi minat dan bakat serta tidak memenuhi standard dan tidak berkembang sebagai destinasi wisata. Dengan melakukan re-desain dari GRJS Bulungan diharapkan dapat mengembangkan kawasan Bulungan dan menjadikan Gelanggang Remaja Bulungan menjadi pionir tempat wisata di kawasan Bulungan. Berfokus pada kegiatan seni pertunjukan yang semakin memudar dari tahun ke tahun diharapkan dapat mengembalikan kehadiran seni di kawasan Bulungan. 


\section{Identifikasi Masalah}

Permasalahan yang teridentifikasi didalam proyek ialah bagaimana pemanfaatan lahan guna menunjang kebutuhan yang sesuai dengan seni pertunjukan dan menjadikan proyek ini sebagai sebuah destinasi wisata. Bagaimana pula dapat mampu mewadahi kegiatan serta kebutuhan komunitas sekitar yang dapat dijadikan tempat untuk mengapresiasi karya kaum seniman.

\section{Tujuan Penulisan}

a. Menghadirkan wadah secara arsitektural yang dapat memfasilitasi segala bentuk apresiasi para pelaku seni dengan standar yang sesuai.

b. Melakukan penataan ulang/re-desain ruang seni pertunjukan di Gelanggang Remaja Bulungan agar dapat memaksimalkan ruang-ruang yang terdapat di GRB.

c. Menjadikan Re-desain Ruang Seni Pertunjukan Gelanggang Remaja Bulungan ini nantinya sebagai salah satu destinasi wisata yang dikunjungi oleh wisatawan lokal maupun mancanegara.

\section{Manfaat Penulisan}

a. Meningkatkan perekonomian di sektor pariwisata.

b. Meningkatkan apresiasi masyarakat mengenai seni pertunjukan.

c. Mengusulkan wadah arsitektural bagi para pengambil keputusan (Dinas Kepemudaan dan Olahraga serta Pemerintah Daerah Jakarta), Pengelola Gelanggang Remaja Jakarta Selatan maupun investor.

\section{METODE}

Pada penelitian kali ini menggunakan pendekatan /metode kualitatif dimana penelitian memanfaatkan teori yang ada sebagai bahan penjelas yang mengangkat permasalahan "kurangnya wadah seni pertunjukan yang memenuhi standar serta ruang apresiasi para pelaku seni di Gelanggang Remaja Jakarta Selatan".

Dialam memperoleh data, terdapat 3 metode yang dipakai antara lain: wawancara, survey lapangan dan studi literatur. Wawancara dilakukan dengan para pelaku seni di Bulungan serta pengelola dari Gelanggang Remaja Jakarta Selatan yang menghasilkan data berupa aktivitas, kegiatan serta kebutuhan dari ruang seni pertunjukan. Survey lapangan dilakukan dengan melakukan observasi yang menghasilkan output berupa mapping. Studi literatur merupakan data skunder yang didapat dari sumber bacaan seperti buku, skripsi, tesis, artikel, majalah maupun koran.

\section{DISKUSI DAN HASIL}

\section{Konsep dan Tema}

Proyek ini berupaya menghadirkan rancangan ruang luar dan bangunan yang dapat terintergrasi dengan kawasan serta konsep dari kawasan tersebut. Dengan pendekatan konsep wisata lingkungan yang merupakan startegi dan arah pengembangan pariwisata di wilayah Kebayoran Baru Jakarta selatan bedasrkan buku "Perencanaan Kawasan Wisata Jakarta" yang dikeluarkan oleh Dinas Pariwisata Provinsi DKI Jakarta.

\section{Hasil Rancangan}

Pemanfaatan ruang luar diaplikasikan pada Area Seni Pertunjukan Gelanggang Remaja Bulungan yang disesuaikan dengan konsep wisata lingkungan. 


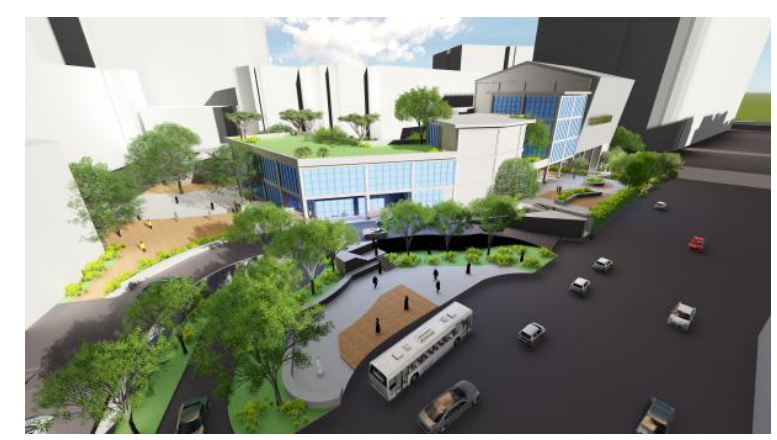

Gambar 1. Perspektif

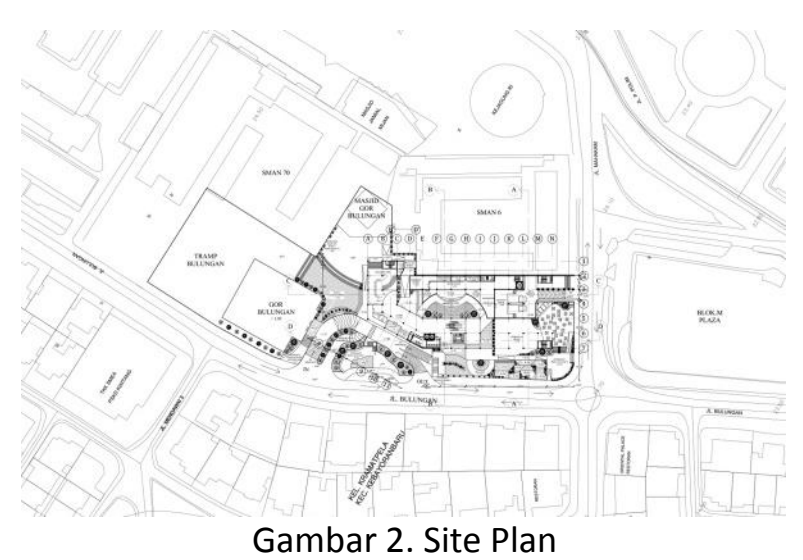

Pada denah lantai dasar pemanfaatan ruang lebih diutamakan untuk kegiatan komunal, galeri, amphiteater serta akses pejalan kaki. Sedangkan area kendaraan untuk parkir dimanfaatkan pada area basement. Selain itu, area loading juga diletakan pada lantai dasar bagian belakang, menggunakan akses untuk loading jalan samping sehingga menjadikan area loading tidak terekspos untuk pengunjung atau pengguna jalan utama.

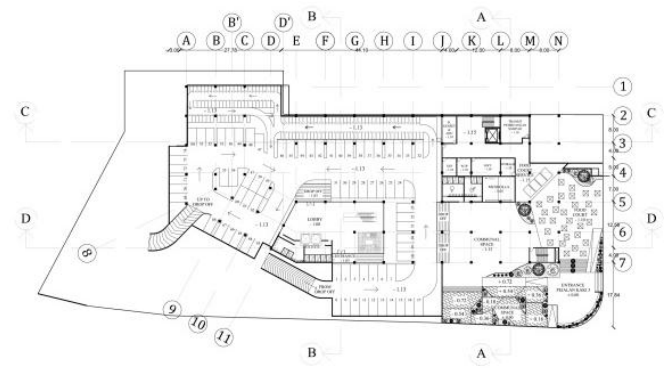

Gambar 3. Denah Basement

Denah lantai basement dimanfaatkan untuk area parkir kendaraan. Area parkir kendaraan juga langsung terhubung dengan area komunal dan foodcourt, selain itu area servis bangunan juga terletak pada area lantai basement.

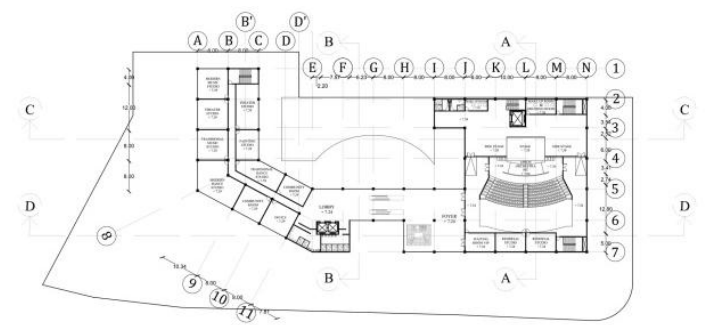

Gambar 4. Denah Lantai 1 
Pada denah lantai 1, terdapat area studio sebagai area berlatih indoor, selain itu belakang panggung auditorium dapat diakses melalui lantai 1.

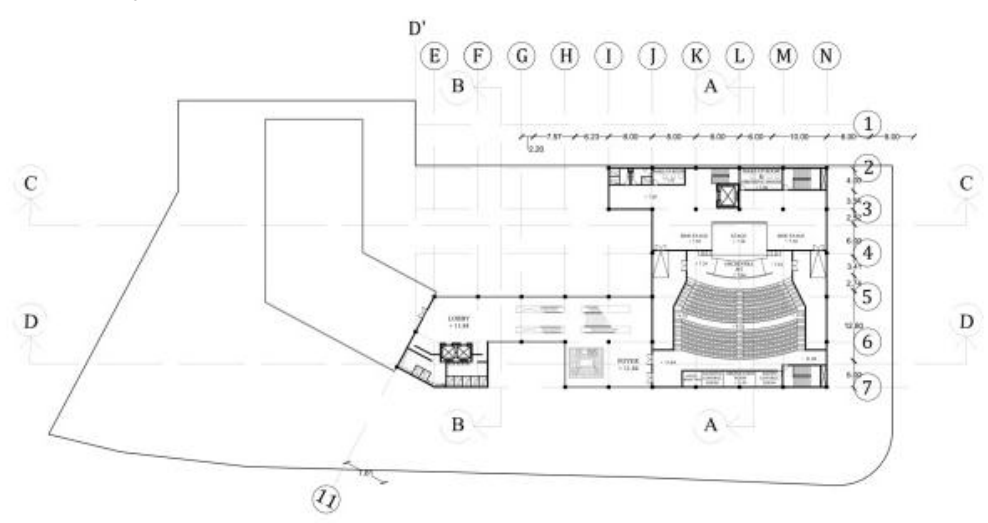

Gambar 5. Denah Lantai 2

Denah lantai 2 dan 3 difokuskan pada area auditorium. Akses utama untuk pengunjung melalui lantai 2 sedangkan lantai 3 merupakan area balkon auditorium.

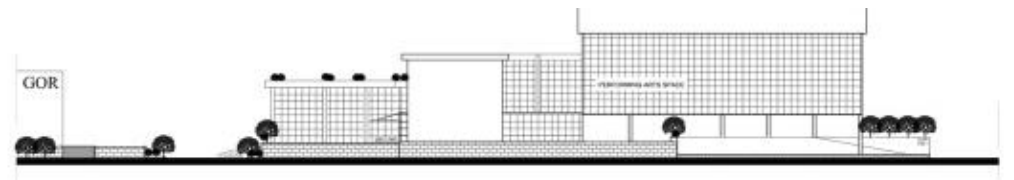

TAMPAK MUKA

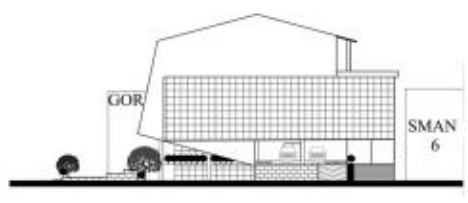

TAMPAK SAMPING KANAN

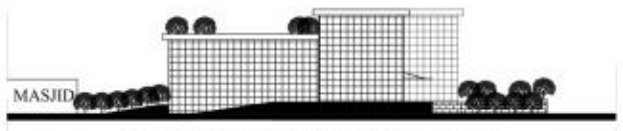

TAMPAK SAMPING KIRI

Gambar 6. Tampak

Dengan menggunakan material tempered glass menjadikan bangunan tidak terlihat padat dan pengunjung tetap dapat merasakan area ruang luar dari lantai 1, 2 maupun 3.

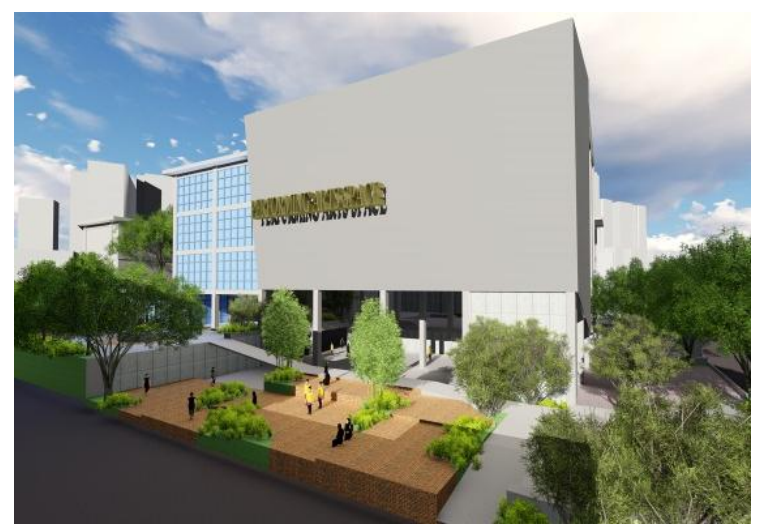

Gambar 7. Perspektif

Pada area auditorium diberikan sign berupa tulisan "Performing Arts Space" yang menandakan bahwa area tersebut merupakan area seni pertunjukan, mengingat Gelanggang Remaja Jakarta Selatan ini tidak hanya digunakan sebagai area seni melainkan juga sebagai gelanggang olahraga. 


\section{KESIMPULAN DAN SARAN \\ Kesimpulan}

Re-desain Area Seni Pertunjukan Gelanggang Remaja Bulungan (GRB) bertujuan untuk mewadahi serta memfasilitasi kegiatan seni di GRB. Selain itu, redesain ini bertujuan menjadikan GRB ini sebagai sebuah destinasi wisata dengan atraksi kesenian yang berada di GRB. Pengolahan ruang luar didesain semenarik mungkin sebagai daya tarik arsitektural dari area seni pertunjukan ini. Selain itu ruang luar juga dapat digunakan sebagai area komunal yang dapat dimanfaatkan sebagai ruang berlatih bagi para seniman.

\section{Saran}

Dalam mengerjakan perancangan dan penulisan mengenai Re-desain Area Seni Pertunjukan Gelanggang Remaja Bulungan diharapkan dapat terus dikembangkan dan dapat dibahas lebih lengkap oleh penulis/peneliti lainnya.

\section{REFERENSI}

Appleton, I., (2012). Buildings for the performing arts. Routledge.

Curedale, R., (2018). Design Thinking: Process \& Methods Guide. Design Community College Incorporated.

Dinas Pariwisata Propinsi DKI Jakarta., (2002). Pariwisata sebagai citra kualitas pertumbuhan kota. Jakarta.

Hayllar, B., (2010). Urban tourism precincts: engaging with the field. In City Spaces-Tourist Places (pp. 21-36). Routledge.

Specht, J., (2014). Architectural Tourism and the Spectaculture. In Architectural Tourism (pp. 133-164). Springer Gabler, Wiesbaden.

Tjahjono, G., (2000). Metode Perancangan, Suatu Pengantar untuk Arsitek dan Perancang.

Zahnd, M., (1999). Perancangan kota secara terpadu. Yogyakarta: Kanisius.

http://gr-js.blogspot.com/p/about-us.html (Diakses 11 Juli 2018, 19:34 WIB)

https://www.cnnindonesia.com/gaya-hidup/20160909111014-275-157209/wadah-anak-

muda-bernama-gelanggang-remaja (Diakses 11 Juli 2018, 19:35 WIB)

http://wartakota.tribunnews.com/2012/10/06/gelanggang-remaja-tertua-di-jakarta (Diakses

11 Juli 2018, 19:55 WIB)

http://www.wikiwand.com/id/Gelanggang_Remaja (Diakses 11 Juli 2018, 19:56 WIB)

https://www.scribd.com/document/340960123/Gelanggang-Remaja-Bulungan (Diakses 11 Juli 2018, 19:56 WIB)

https://id.wikipedia.org/wiki/Gelanggang_Remaja (Diakses 11 Juli 2018, 19:57 WIB)

http://www.tribunnews.com/travel/2015/05/28/warung-apresiasi-alias-wapress-di-bulunganjakarta-lokasi-manggung-nidji-dan-dmasiv-sebelum-tenar (Diakses 11 Juli 2018, 20:18 WIB) https://ms.wikipedia.org/wiki/Metropolis (Diakses 15 Juli 2018, 13:30 WIB)

https://jakarta.go.id/artikel/konten/2025/anies-paparkan-visi-misi-dalam-musrenbang-rpjmddki-2017-2022 (Diakses 15 Juli 2018, 13:37 WIB)

https://id.wikipedia.org/wiki/Pariwisata (Diakses 15 Juli 2018, 13:43 WIB)

http://resthoe.blogspot.com/2013/02/destinasi-wisata-daerah-tujuan-wisata.html (Diakses 15 Juli 2018, 13:54 WIB)

https://id.wikipedia.org/wiki/Seni_pertunjukan (Diakses 15 Juli 2018, 14:14 WIB)

http://www.pelajaran.co.id/2018/19/pengertian-seni-pertunjukan-fungsi-dan-jenis-jenis-senipertunjukan-terlengkap.html\#fungsi-seni-pertunjukan (Diakses 15 Juli 2018, 14:20 WIB)

http://erwingeograf.blogspot.com/2012/02/teori-perkembangan-kota.html (Diakses 9 September 2018, 12:08) 